\title{
Diurnal and seasonal variation in air exchange rates and interzonal airflows measured by active and passive tracer gas in homes
}

Bekö, Gabriel; Gustavsen, Sine; Frederiksen, Marie; Bergsøe, Niels Christian; Kolarik, Barbara; Gunnarsen, Lars; Toftum, Jørn; Clausen, Geo

\section{Published in:}

Building and Environment

Link to article, DOI:

10.1016/j.buildenv.2016.05.016

Publication date:

2016

Document Version

Peer reviewed version

Link back to DTU Orbit

Citation (APA):

Bekö, G., Gustavsen, S., Frederiksen, M., Bergsøe, N. C., Kolarik, B., Gunnarsen, L., Toftum, J., \& Clausen, G. (2016). Diurnal and seasonal variation in air exchange rates and interzonal airflows measured by active and passive tracer gas in homes. Building and Environment, 104, 178-187.

https://doi.org/10.1016/j.buildenv.2016.05.016

\section{General rights}

Copyright and moral rights for the publications made accessible in the public portal are retained by the authors and/or other copyright owners and it is a condition of accessing publications that users recognise and abide by the legal requirements associated with these rights.

- Users may download and print one copy of any publication from the public portal for the purpose of private study or research.

- You may not further distribute the material or use it for any profit-making activity or commercial gain

- You may freely distribute the URL identifying the publication in the public portal 


\section{Diurnal and seasonal variation in air exchange rates and interzonal airflows measured by active and passive tracer gas in homes}

Gabriel Bekö ${ }^{*}$, Sine Gustavsen ${ }^{1}$, Marie Frederiksen², Niels Christian Bergsøe ${ }^{2}$, Barbara Kolarik ${ }^{2}$, Lars Gunnarsen², Jørn Toftum ${ }^{1}$, Geo Clausen ${ }^{1}$

${ }^{1}$ International Centre for Indoor Environment and Energy, Department of Civil Engineering, Technical University of Denmark, Nils Koppels Allé 402, 2800-Lyngby, Denmark

${ }^{2}$ Danish Building Research Institute, Aalborg University, A.C. Meyers Vænge 15, 2450 Copenhagen, Denmark

*Contact email: gab@byg.dtu.dk, phone: (+45) 452540 18, fax: (+45) 45932166

\section{Highlights}

- Air exchange rates and internal airflows were measured in 5 homes during 4 seasons

- Large diurnal, spatial and seasonal variations in AER were observed

- Window opening was a key factor influencing AER

- Large differences were found between AERs measured by the different techniques

- With open doors the air was well mixed within the same floor, not so between floors

\section{Abstract}

Outdoor air delivery to buildings is an important parameter in the assessment of pollutant exposure indoors. Detailed and well controlled measurements of air exchange rates (AER) and interzonal airflows in residential environment are scarce. We measured the outdoor AERs in up to six rooms in five dwellings across four seasons using active tracer gas. Night time AERs were also estimated in the bedrooms based on occupant-generated $\mathrm{CO}_{2}$. Passive tracer gas measurements were performed for comparison. AERs changed frequently during the day. Differences in outdoor AERs were observed between individual rooms. Window opening behavior had a strong influence on AERs, which were highest during occupied daytime periods, lowest in the night; highest in the summer, lowest in the winter. Significant differences were found between AERs measured by the different techniques. The median nighttime AER in all bedrooms across the four seasons was 0.49 $\mathrm{h}^{-1}$ with the active tracer gas technique and $1.20 \mathrm{~h}^{-1}$ with the $\mathrm{CO}_{2}$ method. The average winter AER in the five homes with the passive tracer $\left(0.63 \mathrm{~h}^{-1}\right)$ differed substantially from the corresponding AER measured with the active tracer gas $\left(0.25 \mathrm{~h}^{-1}\right)$. Additionally, we studied the pollutant distribution from one room (source room) and interzonal airflows across the dwellings. The air within a given floor was well mixed, with the average tracer gas concentration in the non-source rooms reaching approximately $70 \%$ of the source room concentration. There was less air movement between different floors. The position of the internal doors had a strong influence on the air movement. 
42 Keywords: Ventilation, Spatial variation, Measurement technique, $\mathrm{CO}_{2}$, Occupant influence

\section{Introduction}

Air exchange rate (AER) is a key parameter in understanding indoor air quality, pollutant concentrations and exposure. In naturally ventilated buildings AER will depend on building characteristics, geographic location, meteorological conditions such as indoor/outdoor temperature differences and wind speed, and occupant behavior [1][2][3][4][5]. Performing accurate AER measurements can be challenging. Various measurement techniques can be chosen depending on the desired number of measurements, the stability of the steady-state conditions, and the experimental limitations [6][7]. Indoor environmental studies mostly rely on passive tracer gas techniques or tracer gas decay measurements, often using occupant-generated $\mathrm{CO}_{2}$ concentrations. The accuracy of these techniques has been widely discussed [8][9]. In most cases these measurements consider the entire space as a single zone, ignoring interzonal airflows and leading to substantial uncertainties [10]. When passive tracer gas techniques are applied, a single average AER value is reported for the entire measured building zone over a certain period of time. AERs vary considerably over time [11]. AERs within a building may differ from room to room or zone to zone, depending on differences in occupant behavior (e.g. window opening) [3][12][13].

Active tracer gas measurement using the constant concentration method allows monitoring the short term changes in multizone buildings [6]. During guarded constant concentration measurements, where the tracer gas concentration in the adjacent zones is maintained at the same level as in the measured zone, airflows between the measured zone and the adjacent zones will not affect the measurements and the determined air exchange rate will be the outdoor air exchange rate (as opposed to total air exchange rate, obtained from e.g. occupant-generated $\mathrm{CO}_{2}$ ). Due to the need of sophisticated equipment and control system, reports of continuous measurements using controlled tracer gas concentrations are scarce [14][7]. Moreover, while the various measurement techniques perform reasonably well under controlled single zone conditions [15], they have not been compared in parallel measurements under real life conditions.

Interzonal flows within buildings strongly influence spatial variation in pollutant concentrations and exposure. This is especially the case when localized pollution sources are present, such as environmental tobacco smoke (ETS). Several studies looked at the migration of ETS between rooms and concluded that considerable exposure to ETS with the source in a single room may occur throughout the home [16][17][18][19]. Few other studies on the airflows within buildings have been 
performed, mostly using passive tracer gas and focusing on the transport of air and pollutants between basements or garages and living areas [20][21][22][23][24] and between industrial zones and offices of mixed-use buildings [25]. Du et al. [12] characterized the AERs and interzonal flows between bedrooms and living areas in 126 households. The study indicated that tighter homes (lower AERs) have higher internal flows. In 26 Japanese residencies, the interzonal air exchange rates (based on interzonal airflows from other rooms as opposed to outdoor air) from bedroom to living/dining room varied between $0.54 \mathrm{~h}^{-1}$ in autumn to $1.6 \mathrm{~h}^{-1}$ in summer, and between living/dining room and bedroom it varied between $0.42 \mathrm{~h}^{-1}$ in autumn and $0.85 \mathrm{~h}^{-1}$ in summer [13]. Even in rooms with very low outdoor AER, interzonal airflows from the other rooms were substantial. These studies applied multi-compartment passive tracer measurements based on steadystate assumptions and did not consider short-term fluctuations. However, the time of occurrence and duration of interzonal airflow variations can be critical in determining pollutant concentrations indoors. Concentrations based on time-weighted average interzonal airflows could be underpredicted [26]. Short term variations in interzonal airflows can mainly arise from internal door opening patterns, but also from window opening and operation of heating and ventilation systems $[17][26][27]$.

Outdoor air delivery to individual rooms within buildings is of interest when interpreting contaminant exposure. This paper characterizes the diurnal, seasonal and spatial variations in AERs, pollutant distribution throughout the building from a single source room and associated interzonal airflows using tracer gas concentration measurements in five homes. The effects of short-term changes in home occupancy and occupant behavior are demonstrated using real-time measurements. Room and house AERs measured simultaneously with different techniques are compared.

\section{Methods}

\subsection{Selected residences}

As part of a study conducted by the research program "Center for Indoor Air and Health in Dwellings” [28], five homes were selected for detailed investigation of their indoor environments, including chemical and microbiological parameters, during the course of one year, from summer 2010 to spring 2011 [29][30]. The homes were not selected to be representative of the Danish building stock. Because of the use of disturbing sampling equipment, the homes were chosen among colleagues and acquaintances of the project team, with the intention of reducing the risk of non-compliance or subject withdrawal from the project. However, they were selected to include both single family houses, a row house and an apartment, and dwellings of different age and means of ventilation. All homes were situated in urban areas within a 40-km radius of Copenhagen, 
111 Denmark. Characteristics of the homes are listed in Table 1. The layouts of the homes are shown in 112 Figure S1.

113

114

115

\subsection{Air exchange rates}

In each season of the year continuous air exchange rate (AER) measurements were performed during 2-4 days periods, which often included weekends. The measurements in the five homes were performed during five successive weeks (Table S1). An Innova 1312 Photoacoustic Multi-gas Monitor coupled with an Innova Multipoint Sampler and Dozer 1303 (Luma-Sence Technologies A/S, Ballerup, Denmark) was used. Prior to the measurements, the instrument was confirmed not to show any sign of leakage. Yet, whenever possible, the tracer gas sampler and dozer were placed behind closed doors in a room that was not directly investigated in the experiment. A constant concentration of 4 ppm of tracer gas (Freon ${ }^{\circledR} 134 \mathrm{a}$ ) was maintained in up to six rooms in each dwelling, covering on average $83 \%$ of the total volume of the dwellings (Table 1). For each day of the measurement period, the occupants filled in a questionnaire. They indicated the periods when the home was occupied vs. unoccupied, the time they spent in the bedroom, the position of the windows in various rooms and the position of the bedroom door during the night (open/closed). A value was assigned to the position of the windows (closed, assigned value 0 ; ajar, assigned value 1; open, assigned value 2). The corresponding value was assigned to each time step for which a tracer gas concentration and AER was obtained (every 3-4 minutes in each room). The average window position, being a time-weighted continuous variable, was then calculated for each time period that was separately analyzed. For each measured room the AERs were determined for the entire period and separately for the periods when the home was unoccupied, occupied in the daytime and nighttime (00:00-06:00 o'clock). The average overall AER in each dwelling was calculated both as the volume-weighted average of the AERs of each room and as the sum of the obtained average airflows into the measured rooms divided by the corresponding total volume. We assumed that the average outdoor AER in the unmeasured part of the dwelling was the same as the average AER in the measured rooms. This is reasonable, given the fact that actual measurements covered the majority of the dwellings by volume (between $\sim 60 \%$ and $~ 95 \%$; Table 1 ). The occupants were asked not to alter their normal behavior during measurements.

The concentrations of $\mathrm{CO}_{2}$ in the bedrooms were measured by CARBOCAP ${ }^{\circledR} \mathrm{CO}_{2}$ monitors (GMW22, Vaisala, Finland). The data were logged every 5 minutes by HOBO U12-012 dataloggers (Onset Computer Corp., USA). $\mathrm{CO}_{2}$ data obtained in the time period between 00:00 and 6:00 for each measured night were extracted for calculation of the AERs. This time period was selected to represent the conditions when the occupants spent most of the time in the bedroom. The 
activity and occupancy were assumed to be constant during the night. AERs based on occupantgenerated $\mathrm{CO}_{2}$ were calculated according to the procedure described in detail by Bekö et al. [31] .

The PerFluorocarbon Tracer (PFT) technique [32] was applied to measure the monthly average AERs during the whole year, as previously described by Frederiksen et al. [33]. In brief, two types of tracer gas were used, perfluoro-methyl-cyclopentane (PMCP) and perfluoro-methyl-cyclohexane (PMCH). Only one type was used in each dwelling. Hence, the dwellings were treated as single zones. PFT sources along with adsorption tube samplers were mounted in the dwellings. The adsorption tube samplers were changed every month, resulting in monthly average AERs. The amount of tracer adsorbed in the samplers was analyzed using thermal desorption and gas chromatography and the AER was calculated from the concentration, measured temperature, known emission rates and the volume of the dwelling. Details of the PFT technique, including analysis of tracer gases and estimation of tracer gas emissions have been described by Leaderer et al. [34]. For comparison with the AERs from the other measurement techniques, the monthly AERs obtained by the PFT technique during the months corresponding to the other measurements were used. For more direct comparison of the air exchange rate measurement techniques, the PFT technique was also applied for a 5-day period overlapping with the active tracer gas measurements in each home during winter.

\subsection{Pollutant distribution and interzonal flows}

Before each AER measurement the distribution of a simulated pollutant from a source point across the dwelling was measured over a period of about 26 hours. Constant concentration of tracer gas (4 ppm) was maintained in a selected room and its concentration was monitored in the rest of the rooms (identical to the AER measurements). The selected source rooms are listed in Table S1. Steady-state concentrations in the source rooms were reached in less than an hour after the measurements began. The data obtained after this point were used for analyses. The average tracer gas concentration was calculated in each source room and each measured non-source room. 30minute running average tracer gas concentrations were used to calculate the fractions of source room concentrations in each non-source room for each measurement time-step (approximately every four minutes). These fractions were then averaged over the total measurement period. Since two of the homes had two floors where measurements were performed, we also present the results separately for the source floors and non-source floors. The results were additionally stratified over home occupancy and distance from the source room (in case of single-floor houses). The source room was considered Zone 1 . Zone 2 consisted of rooms immediately adjacent to the source room, while other rooms belonged to Zone 3 . The airflows between adjacent rooms, between the source 
room and the rest of the dwelling and between two different floors were calculated from the obtained data. Additionally, the fraction of the total airflow entering a given space that arises from another space (interzonal flow proportions) was calculated. Details of these calculations can be found in the Supplementary Material.

\subsection{Statistical analyses}

Statistical analyses were made in STATA software, release 12.1 for Windows (StataCorp LP, College Station, Texas, USA). Differences in AERs and concentration fractions by season were tested using Kruskal-Wallis test. Differences in tracer gas concentrations, AERs and window opening between various occupancy periods, as well as differences between AERs measured by the different techniques were tested using Wilcoxon matched-pairs signed-rank test. Two-sample Wilcoxon rank-sum test and two-sample t-test were used to look for differences in tracer gas concentrations and concentration fractions between different floors or zones. We used linear regression to examine the association between AER and outdoor temperature or average window position and between AERs obtained by different techniques.

\section{Results and Discussion}

\subsection{Diurnal and seasonal variation in air exchange rates}

Large differences in AERs were observed between the five dwellings (Table 2). The highest AER was consistently measured in home E, which was a relatively new apartment building with mechanical exhaust ventilation. This is consistent with earlier results from Scandinavia [35][36]. The differences among the single family homes were likely caused by the different construction and age of the buildings, weather conditions during the measurements and occupant behavior [37][38]. The AER in each room fluctuated during the day. An example of the diurnal changes in room AERs is shown on Figure S2. The diurnal trends in AER of the entire homes averaged across all measurement days are shown for each home and season in Figure 1. The highest average AERs were measured during the day. The strong influence of occupant behavior on the AER is supported by the fact that significantly higher AERs were measured during daytime periods when the homes were occupied, compared to nights and unoccupied periods. The windows were open significantly more during the occupied daytime periods (Table 3). Airing by periodic opening of windows is common in Scandinavia throughout the year. A linear relationship between the median AER and the average window position in Table 3 had a coefficient of determination $\mathrm{R}^{2}=0.66$. 
215 In dwellings, the Danish building code requires a minimum outdoor air supply rate of $0.3 \mathrm{~L} / \mathrm{s} / \mathrm{m}^{2}$

216 heated floor area to remove moisture from the indoor air. However, moisture generation will 217 typically not be constant, but will vary during the day with the occupants' activities. Allowing 218 variation of the outdoor air supply rather than specifying a constant minimum may be a more 219 efficient means of ventilating dwellings. Currently, it is not clear how the criteria for a minimum 220 outdoor air supply rate that accounts for the variation in moisture generation should be specified.

221 Some guidance may be found in Table 3, which shows how the outdoor air supply rate was lower at 222 night or unoccupied day periods than when the occupants were present in the dwelling. In particular 223 during the winter and spring, the area specific outdoor air supply rate was lower than what's 224 specified in the building code, when the occupants were sleeping or not present. When the occupants were present and awake, their activities in the dwelling resulted in increased supply of outdoor air. Thus, in the five dwellings investigated in this study, the outdoor air supply seemed to trace the expected variation in moisture generation.

Significant seasonal variation in AER was observed (Tables 2 and 3). In all homes, the lowest AERs, mostly below $0.5 \mathrm{~h}^{-1}$, were measured in the winter and autumn, highest in the summer. This is typical for buildings in moderate climate that use primarily natural ventilation [1][13][20][39]. In dwellings that have no balanced mechanical ventilation, the actual AER is strongly influenced by changing occupant behavior, especially window opening [4][40][41], which tends to be more extensive in the summer [13][42]. We observed more window opening during warmer seasons (Table 3). A moderate positive linear relationship between outdoor temperature and AER was obtained, with the coefficient of determination $\mathrm{R}^{2}=0.65$ ( $\mathrm{p}<0.001 ; \mathrm{n}=19$; using AERs in Table 2 for each season and home, excluding one data point - an unusually high summer AER in home E. $\mathrm{R}^{2}$ with this data point included was 0.41).

The large effect of window opening on AER has been documented in a number of studies [3][31][43]. Howard-Reed et al. [5] found that window opening increased the air exchange rate by 0.10 to $2.8 \mathrm{~h}^{-1}$. Wallace et al. [3] observed that temperature differences could not account for AERs above $0.8 \mathrm{~h}^{-1}$. A strong seasonal effect was noted with windows open more than half the time during the summer months and closed more than $90 \%$ of the time during the autumn and winter months. Wilson et al. [44] noted that in the Los Angeles area, AER increased with the ambient temperature between 11 and $24{ }^{\circ} \mathrm{C}$, then decreased as the temperature increased above $24{ }^{\circ} \mathrm{C}$. The authors argued that people open doors and windows more often when the outside temperature is between $19-24{ }^{\circ} \mathrm{C}$, and they keep their homes tighter at colder and hotter outdoor conditions. 
There were substantial differences in AERs between rooms within the dwellings (Figure S2; see also the relatively large standard deviations in Table 2). In the study by Wallace et al. [3], the mean relative standard deviation of the hourly average AERs across all rooms in a single dwelling was 15\%. Du et al. [12] reported bedroom AERs approximately twice as high as whole-house AERs, suggesting that windows were frequently open in bedrooms and that they may have large exterior wall-to-volume ratio, increasing air infiltration. Shinohara et al. [13] reported slightly higher AERs in the bedrooms in the summer, compared to living rooms and kitchens, while the opposite trend was observed in the other seasons. Bekö et al. [41] found significantly lower AERs in bedrooms located on the ground floor of the dwelling, in comparison with bedrooms located on the first floor or higher. Du et al. [20] compared AER measurements in basements and in corresponding residencies in 170 houses. AERs in basements were consistently higher than in the living areas. On the other hand, the differences between weekly mean AERs measured in 390 entire homes and in the children's bedrooms within these houses were very small [35].

\subsection{Comparison of AER measurement techniques}

The seasonal trends were similar for AERs determined from the constant tracer gas concentration and from occupant-generated $\mathrm{CO}_{2}$ (Table 4). However, at the median level, the AERs in the bedrooms during night determined from $\mathrm{CO}_{2}$ were more than twice as high as the corresponding AERs measured by tracer gas. The median nighttime AER in all bedrooms across the four seasons was $0.49 \mathrm{~h}^{-1}$ with the tracer gas technique and $1.20 \mathrm{~h}^{-1}$ with the $\mathrm{CO}_{2}$ method (Table S2). The relatively strong linear relationship between the AERs measured by the two techniques is indicated on Figure 2.

The PFT measurements captured the differences between the dwellings, but did not show the same variation across the seasons as the other techniques (Tables 4 and 5; see also Figure 2 in Frederiksen et al. [33] for monthly AER in the five homes across seven months). It is therefore not surprising that the 5-day average AERs were very similar to the average AERs for the corresponding months in each home (Table 5). These values differed substantially from the AERs measured with the active tracer gas technique. The correlation between the average AERs in the five homes during the four seasons obtained by the two techniques was weak $\left(R^{2}=0.22 ; p>0.05\right)$.

All of the techniques use certain assumptions and have their limitations. They rely on steady-state and well mixed conditions. The $\mathrm{CO}_{2}$ method assumes uniform $\mathrm{CO}_{2}$ concentration throughout the space and it assumes that the $\mathrm{CO}_{2}$ generation, outdoor $\mathrm{CO}_{2}$ concentration and ventilation rate remain constant during the measurement period. Interzonal flows constitute a problem, and 
therefore this technique often provides an estimate of the total airflow into the bedroom, including airflows from adjacent spaces. Bekö et al. [31] estimated that AERs from a single-zone mass balance of $\mathrm{CO}_{2}$ can have a relative error as high as $120 \%$. The error depends on the occupancy in the adjacent rooms, the true air exchange rate and the amount of air flowing from the adjacent room to the measured room.

The accuracy of AER measurements using passive tracer has received considerable attention. A potential problem with this technique is that for accurate measurements it requires a relatively long measurement time and it assumes that ventilation is constant over that time [6]. This assumption is difficult to satisfy in naturally ventilated dwellings, where occupant behavior can cause frequent changes in AER. Mathematical models indicated that, when applying only one tracer (single-zone), this technique may underestimate the average AER by up to 30\% [8]. This negative bias is due to the fact that the reciprocal of the average tracer concentration, which is the item measured by the passive sampler, is not identical to the average reciprocal tracer concentration, which is the item needed to calculate ventilation rates [34]. Under typical uncontrolled field conditions (e.g., open windows), the error can be on the order of a factor of two [9]. The use of multiple tracers (multizone measurement) eliminates some of the limitations associated with the single passive tracer technique [8][10]. In our case, however, the PFT technique often overestimated the AERs obtained with the active tracer gas measurements. This may occur if the tracer gas adsorbs not only on the sorption material in the samplers, but also on surfaces within the measured space. Dorer et al. [45] concluded that the PFT technique may overestimate airflow rates due to such sink effects by a factor of 1.2 to 2.2. While this is usually assumed not to be the case in typical dwellings, some adsorption has been indicated to occur in dwellings with fleecy surfaces [33]. Moreover, limited number and imperfect positioning of the PFT sources and samplers may have led to non-uniform tracer concentrations. This may have especially been the case in home B, a three-floor home where PFT sources were not placed in the entrance/staircase between the living area and the sleeping area, a room with relatively large volume, in order to avoid the direct effect of the main entrance on the source. Indeed, the PFT technique overestimated the AER from the active tracer gas measurements the most in this home. It is also noteworthy, that the PFT technique and the active tracer technique treated the volume of the measured space differently when determining AERs. The overall AER from the active tracer technique in each dwelling was based on the total volume of the rooms where measurements took place. The PFT technique relied on the total volume of the entire dwellings, although PFT sources and samplers were not placed in all rooms. 
Active tracer gas measurement using the constant concentration method is believed to be the most accurate ventilation measurement technique available in buildings where multizone effects are important [6]. Its error depends on the measurement duration and it assumes that there is no difference between the mean concentration during the measurement period and the target concentration. In case of guarded measurements, it is also assumed that the tracer gas in all surrounding rooms is at the target concentration. These conditions often cannot be met in a dynamic environment with frequent changes in AERs of the various rooms/zones. In most of the dwellings in our study, the six sampling/dosing channels were sufficient to cover nearly all major rooms (guarded measurements). We therefore assert that our measurements reasonably reflect outdoor AERs. However, in dwellings where we could not place a sampling and dozing point in all of the rooms, a constant tracer gas concentration could not be guaranteed throughout the entire dwelling. Interzonal flows between the measured rooms and spaces with lower tracer gas concentration would then lead to overestimated outdoor AER in the measured rooms. Another source of uncertainty in home $\mathrm{E}$ (apartment) may be the potential leakage between adjacent zones (neighboring apartment and staircase) [46]. Additionally, the ideal positions of the sampling and dozing points may have been restricted by the occupants and room functionality [47]. However, air mixing in most rooms was likely satisfactory, especially during occupied periods (see following section).

\subsection{Pollutant distribution and interzonal flows}

The average tracer gas concentrations in all dwellings reached about $60 \%$ of the source room concentration (Table 6). The average tracer gas concentration in the non-source rooms, relative to the source room was somewhat lower in the summer, when outdoor AERs were highest. In the two houses that had two floors (homes B and D), the average tracer gas concentration over the four seasons on the source floors (without the source room) was $3.0 \mathrm{ppm}$. Similar average concentration on the source floors was obtained in the single-floor homes. Significantly lower average concentration was achieved on the non-source floors of homes B and D (1.2 ppm). Together with the lowest interzonal flow proportions between the two floors compared to the rest of the values in Table S3, these results indicate that the air within a given floor is reasonably well mixed, while there is limited air movement between different floors. Van Ryswyk et al. [10] calculated the ratios of perfluorocarbon tracer concentrations in the source floor and the adjacent floor. Median values for these ratios were 2.0 and 2.3, depending on whether the source floor was the main floor or the basement/second floor, respectively. However, we observed episodes when the difference in concentrations on the two floors was small (e.g. Figure 3, afternoon of 13.1.2011). This can occur under certain conditions that may influence airflow directions, such as favorable temperature differences, combination of open windows and doors and occupant movement (e.g. early morning 
of 14.1.2011). Generally, periods of active presence of occupants disrupted the steady state conditions compared to night or unoccupied periods, reflecting more air movement in the dwellings. Du et al. [20] measured the highest portion of air entering the living zone from basement in the winter, lowest in the summer. The authors concluded that these results reflect enhanced stack effect in the winter and increased natural ventilation in the summer. Similar conclusion was drawn by Dodson et al. [23].

The position of the internal doors can influence the air movement between rooms [17][26][27]. An open door between two adjacent rooms or zones can make multiple rooms behave as a single compartment [19]. For example, the bedroom door in house C was ajar in the night but was most likely fully open during daytime (data on door opening was only available for night time). Indeed, the average ratio of bedroom to source room concentration during night was $41 \%$, while during daytime it was $80 \%$. During the measurements in the five homes there were altogether five episodes when the door to a non-source bedroom was closed. All these rooms had closed windows during these periods. In most cases the tracer gas concentration was decreasing during this time, after it had built up prior to closing the door (e.g. Figure S3 B). There were four episodes when the door of the source room was closed (e.g. Figure 4). The average concentration in the rest of the rooms was lower during these periods compared to the concentration during the entire measurement period. Since extensive airing often resulted in lower concentrations in the non-source rooms (Figures S3 and S4), it's important to note that all these closed-door episodes occurred in the autumn and winter, when the windows were mostly closed and the ventilation rates were low.

The present results have limitations. Our calculations assume uniform concentrations within the measured rooms. Furthermore, the measurements of interzonal airflows were performed over relatively short periods of time. When rapid changes in the conditions occurred, the calculated average concentrations may not represent the steady state conditions well. Information on the position of the internal doors was only available for the bedrooms during night. Diaries about occupant activities such as window opening are often inaccurate compared to data supported by measurements. Studies conducted in a larger number of homes among the general population, using a second active tracer gas (two-zone approach) and collecting more reliable information about activities that affect AER and interzonal airflows, are warranted. It should also be noted that somewhat different results may be obtained in a different climate and in buildings with different characteristics than those included in this study (e.g. with balanced mechanical ventilation). 
390 Air exchange rates were measured to be highest in summer, lowest in winter. They were highest 391 during occupied daytime periods. Airflows from outdoors into the rooms as well as airflows 392 between rooms within a dwelling can be dynamic, leading to frequently changing air exchange rates during the day and even differences in AERs between rooms. Occupant behavior, especially window and door opening, is a major driver of these changes and to a certain degree of the differences in outdoor AER between seasons as well as between dwellings. However, the limitations of the different measurement techniques should be born in mind, when reporting outdoor AERs and comparing them between studies. Large differences between AERs measured by three different techniques were observed. Bedroom AERs determined from occupant-generated $\mathrm{CO}_{2}$ (total AER) were more than twice as high as the corresponding AERs from the active tracer gas measurements using the constant concentration method (outdoor AER).

Measurements of pollutant distribution throughout the dwelling from a single source revealed that the air within a given floor was well mixed, while there was limited air movement between different floors. The average tracer gas concentration in the non-source rooms was about $70 \%$ of the source room concentration on the same floor, but below 30\% on a floor different from that of the source room. The average tracer gas concentration in the non-source rooms, relative to the source room, was lower in the summer, when extensive airing took place and AERs were high. At the same time, the airflow rates between adjacent rooms were highest in the summer. The position of the internal doors had a strong influence on the air movements within the dwelling. These are some of the most comprehensive measurements of AER and airflows in residencies under real life conditions. The results may help in the evaluation of the spatial and temporal factors affecting occupant exposure to indoor pollutants in residential environments.

\section{Acknowledgments}

This work was part of the Centre for Indoor Air and Health in Dwellings (CISBO) study, supported by the Realdania foundation. We thank the participating families for their cooperation.

\section{References}

[1] Murray, D.M., Burmaster, D.E. Residential air exchange-rates in the United States - empirical and estimated parametric distributions by season and climatic region. Risk Anal 1995;15(4):459-465.

[2] Yamamoto, N., Shendell, D.G., Winer, A.M., Zhang, J. Residential air exchange rates in three major US metropolitan areas: Results from the Relationship among Indoor, Outdoor, and Personal Air Study 1999-2001. Indoor Air 2010;20:85-90. 
[3] Wallace L.A.,Emmerich, S.J.,Howard-Reed, C. Continuous measurements of air change rates in an occupied house for 1 year: the effect of temperature, wind, fans, and windows. J Expo Anal Environ Epidemiol 2002;12(4):296-306.

[4] Iwashita, G., Akasaka, H. The effects of human behavior on natural ventilation rate and indoor air environment in summer - a field study in southern Japan. Energy and Building 1997;25(3):195-205.

[5] Howard-Reed, C., Wallace, L.A., Ott, W.R. The effect of opening windows on air change rates in two homes. J Air Waste Manage Assoc 2002;52(2):147-159.

[6] Sherman, M.H. Tracer-gas techniques for measuring ventilation in a single zone. Build. Environ 1990;25:365-374.

[7] Persily, A.K. Field measurement of ventilation rates. Indoor Air 2016;26:97-111.

[8] Sherman, M.H. Analysis of errors associated with passive ventilation measurement techniques. Build. Environ. 1989;24:131-139.

[9] Sherman, M.H., Walker, I.S., Lunden, M.M. Uncertainties in air exchange using continuousinjection, long-term sampling tracer-gas methods. Int. J. Vent. 2014;13:13-28.

[10] Van Ryswyk, K., Wallace, L., Fugler, D., MacNeill, M., Heroux, M.E., Gibson, M., Guernsey, J.R., Kindzierski, W., Wheeler, A.J. Estimation of bias with the single-zone assumption in measurement of residential air exchange using the perfluorocarbon tracer gas method. Indoor Air 2015;25:610-619.

[11] Persily, A. What we think we know about ventilation. In: Proceedings of Indoor Air 2005, Beijing, China; p.24-39.

[12] Du, L., Batterman, S., Godwin, C., Chin, J.-Y., Parker, E., Breen, M., Brakefield, W., Robins, T., Lewis, T. Air change rates and interzonal flows in residences, and the need for multi-zone models for exposure and health analyses, Int. J. Environ. Res. Public Health 2012;9:4639_ 4661.

[13] Shinohara, N., Kataoka, T., Takamine, K. Gamo, M. Distribution and variability of the 24-h average air exchange rates and interzonal flow rates in 26 Japanese residences in 5 seasons, Atmos.Environ. 2011;45: 3548-3552.

[14] Persily, A.K., Levin, H. Ventilation measurements in IAQ studies: problems and opportunities. In: Proceedings of Indoor Air 2011, 12th International Conference on Indoor Air Quality and Climate, 2011; manuscript no. 566.

[15] Stavova, P., Melikov, A.K., Sundell, J., Naydenov, K.G. A new approach for ventilation measurement in homes based on $\mathrm{CO}_{2}$ produced by people - laboratory study. In: Proceedings of $17^{\text {th }}$ International Conference on Air Conditioning and Ventilation, Prague, 2006;291-296.

[16] Miller, S.L. and Nazaroff, W.W. Environmental tobacco smoke particles in multizone indoor environments. Atmos. Environ. 2001;35:2053-2067.

[17] Klepeis, N.E., Nazaroff, W.W. Mitigating residential exposure to secondhand tobacco smoke. Atmospheric Environment 2006;40:4408-4422.

[18] Löfroth, G. Environmental tobacco smoke: Multicomponent analysis and room-to-room distribution in homes. Tobacco Control 1993;2:222-225.

[19] Ott, W.R., Klepeis, N.E., Switzer, P. Analytical solutions to compartmental indoor air quality models with application to environmental tobacco smoke concentrations measured in a house. J. Air Waste Manage. Assoc. 2003;53:918-936.

[20] Du, L., Batterman, S., Godwin, C., Rowe, Z., Chin, J.-Y. Air exchange rates and migration of VOCs in basements and residences. Indoor Air 2015;25:598-609. 
[21] Batterman, S., Jia, C.R., Hatzivasilis, G. and Godwin, C. Simultaneous measurement of ventilation using tracer gas techniques and VOC concentrations in homes, garages and vehicles. J. Environ. Monit. 2006;8:249-256.

[22] Batterman, S., Jia, C.R. and Hatzivasilis, G. Migration of volatile organic compounds from attached garages to residences: a major exposure source. Environ. Res. 2007;104:224-240.

[23] Dodson, R.E., Levy, J.I., Shine, J.P., Spengler, J.D. and Bennett, D.H. Multi-zonal air flow rates in residences in Boston, Massachusetts. Atmos. Environ. 2007;41:3722-3727.

[24] Dodson, R.E., Levy, J.I., Spengler, J.D., Shine, J.P. and Bennett, D.H. Influence of basements, garages, and common hallways on indoor residential volatile organic compound concentrations. Atmos. Environ. 2008;42:1569-1581.

[25] Jia, C., Batterman, S., Godwin, C., Charles, S., Chin, J.-Y. Sources and migration of volatile organic compounds in mixed-use buildings. Indoor Air 2010;20:357-369.

[26] McGrath, J.A., Byrne, M.A., Ashmore, M.R., Terry, A.C., Dimitroulopoulou, C. A simulation study of the changes in PM2.5 concentrations due to interzonal airflow variations caused by internal door opening patterns. Atmospheric Environment 2014;87:183-188.

[27] Ferro, A.R., Klepeis, N.E., Ott, W.R., Nazaroff, W.W, Hildemann, L.M., Switzer, P. Effect of interior door position on room-to-room differences in residential pollutant concentrations after short-term releases. Atmos. Environ. 2009;43:706-714.

[28] Sigsgaard, T., Clausen, G., Gunnarsen, L., Loft, S., Riddervold, I.S. and Wolkoff, P. 2011. The Danish Centre for Indoor Air and Health in Dwellings - CISBO. In: Proceedings of Indoor Air 2011; manuscript no 421.

[29] Frankel, M., Timm, M., Hansen, E.W., Madsen, A.M. Comparison of sampling methods for the assessment of indoor microbial exposure. Indoor Air 2012;22:405- 414.

[30] Frankel, M., Bekö, G., Timm, M., Gustavsen, S., Hansen, E.W., Madsen, A.M. Seasonal variation of indoor microbial exposures and their relations to temperature, relative humidity and air exchange rates. Applied and Environmental Microbiology 2012;78:23, 8289-8297.

[31] Bekö, G., Lund, T., Toftum, J., Clausen, G. Ventilation rates in bedrooms of 500 Danish children, Building and Environment 2010;45(10):2289-2295.

[32] Dietz, R.N., Cote, E.A. Air infiltration measurements in a home using a convenient perfluorocarbon tracer technique. Environment International 1982;8(1-6):419-433.

[33] Frederiksen, M., Bergsøe, N.C., Kolarik, B., Spilak, M., Bekö, B., Gustavsen, S., Clausen, G., Gunnarsen, L. Seasonal variation in monthly average air change rates using passive tracer gas measurements. In: Proceedings of Indoor Air 2011; manuscript no. 317.

[34] Leaderer, B.P., Schaap, L., Dietz, R.N. Evaluation of the perfluorocarbon tracer technique for determining infiltration rates in residences. Environmental Science and Technology 1985;19(12):1225-1232.

[35] Bornehag, C.G., Sundell, J., Hagerhed-Engman, L., Sigsgaard, T. Association between ventilation rates in 390 Swedish homes and allergic symptoms in children. Indoor Air 2005; $15: 275-280$.

[36] Langer, S., Bekö, G. Indoor air quality in the Swedish housing stock and its dependence on building characteristics. Building and Environment 2013;69:44-54.

[37] Persily, A., Musser, A., Emmerich, S.J. Modeled infiltration rate distributions for U.S. housing. Indoor Air 2010;20:473-485.

[38] Breen, M.S., Burke, J.M., Batterman, S.A., Vette, A.F., Godwin, C., Croghan, C.W., Schultz, B.D., Long, T.C. Modeling spatial and temporal variability of residential air exchange rates for 
the Near-Road Exposures and Effects of Urban Air Pollutants Study (NEXUS). Int. J. Environ. Res. Public Health 2014;11:11481-11504.

[39] Langer, S., Bekö, G., Bloom, E., Widheden, A., Ekberg, L. Indoor air quality in passive and conventional new houses in Sweden. Building and Environment 2015;93:92-100.

[40] Fabi, V., Andersen, R.V., Corgnati, S., Olesen, B.W. Occupants’ window opening behaviour: A literature review of factors influencing occupant behaviour and models. Building and Environment 2012;58:188-198.

[41] Bekö, G., Toftum, J., Clausen, G. Modeling ventilation rates in bedrooms based on building characteristics and occupant behavior. Building and Environment 2011;46(11):2230-2237.

[42] Abt, E., Suh, H.H., Allen, G., Koutrakis, P. Characterization of indoor particle sources: A study conducted in the metropolitan Boston area. Environ. Health Perspect 2000;108:35-44.

[43] Mølgaard, B., Ondracek, J., Stavova, P., Dzumbova, L., Bartak, M., Hussein, T., Smolik, J. Migration of aerosol particles inside a two-zone apartment with natural ventilation: A multizone validation of the multi-compartment and size-resolved indoor aerosol model. Indoor and Built Environment 2014;23(5):742-756.

[44] Wilson, A.L., Colome, S.D., Tian, Y., Becker, E.W., Baker, P.E., Behrens, D.W., Billick, I.H., Garrison, C.A. California residential air exchange rates and residence volumes. Journal of Exposure Analysis and Environmental Epidemiology 1996;6:311-326.

[45] Dorer, V., Gehrig, R., Hill, M., Weber, A. Validation tests for a passive tracer gas technique. Proceedings of Roomvent 2000, “Air Distribution in Rooms: Ventilation for Health and Sustainable Environment", Reading, UK, 2000; Volume 1:349-354.

[46] Hult, E.L., Sherman, M.H. Estimates of Uncertainty in Multi-Zone Air Leakage Measurements. International Journal of Ventilation 2014;12(4):359-368.

[47] Van Buggenhout, S., Van Brecht, A., Eren Özcan, S., Vranken, E., Van Malcot, W., Berckmans, D. Influence of sampling positions on accuracy of tracer gas measurements in ventilated spaces. Biosystems Engineering 2009;104:216-223. 


\section{$543 \quad$ Figure captions}

544 Figure 1. Diurnal variation in outdoor AER in the five homes during four seasons: a. summer, b. 545 autumn, c. winter, d. spring. Note the different range of the vertical axes. Each 4-hour interval is an 546 average of the corresponding time intervals over several days. The overall AER in each dwelling 547 was calculated from the total outdoor airflow into the measured rooms (sum of average flows for 548 each room during the given 4-hour period) and the total volume of these rooms.

549

550

551

552

553 554 555 556 557 558 559 560 561 562

Figure 2. Relationship between bedroom air exchange rates during night determined by active tracer gas measurement and from occupant generated $\mathrm{CO}_{2}$. Each data point represents the average AER over several nights in a given bedroom within a season $(\mathrm{p}<0.001 ; n=39 ; 10$ bedrooms over 4 seasons, one bedroom was excluded in the autumn due to no occupants).

Figure 3. Results of the interzonal flow measurements in home B during winter. The house has two floors. The door between the lower floor and the staircase leading upstairs was closed overnight and presumably during the unoccupied daytime. Bedroom doors were open during the night. The source room was the kitchen, which was on the same floor as the living room.

Figure 4. Results of the interzonal flow measurements in home A in winter. Note that the door of the source room (child room) was closed overnight. 
Figures - Color figures for online only. B\&W Figures for print provided below.

564
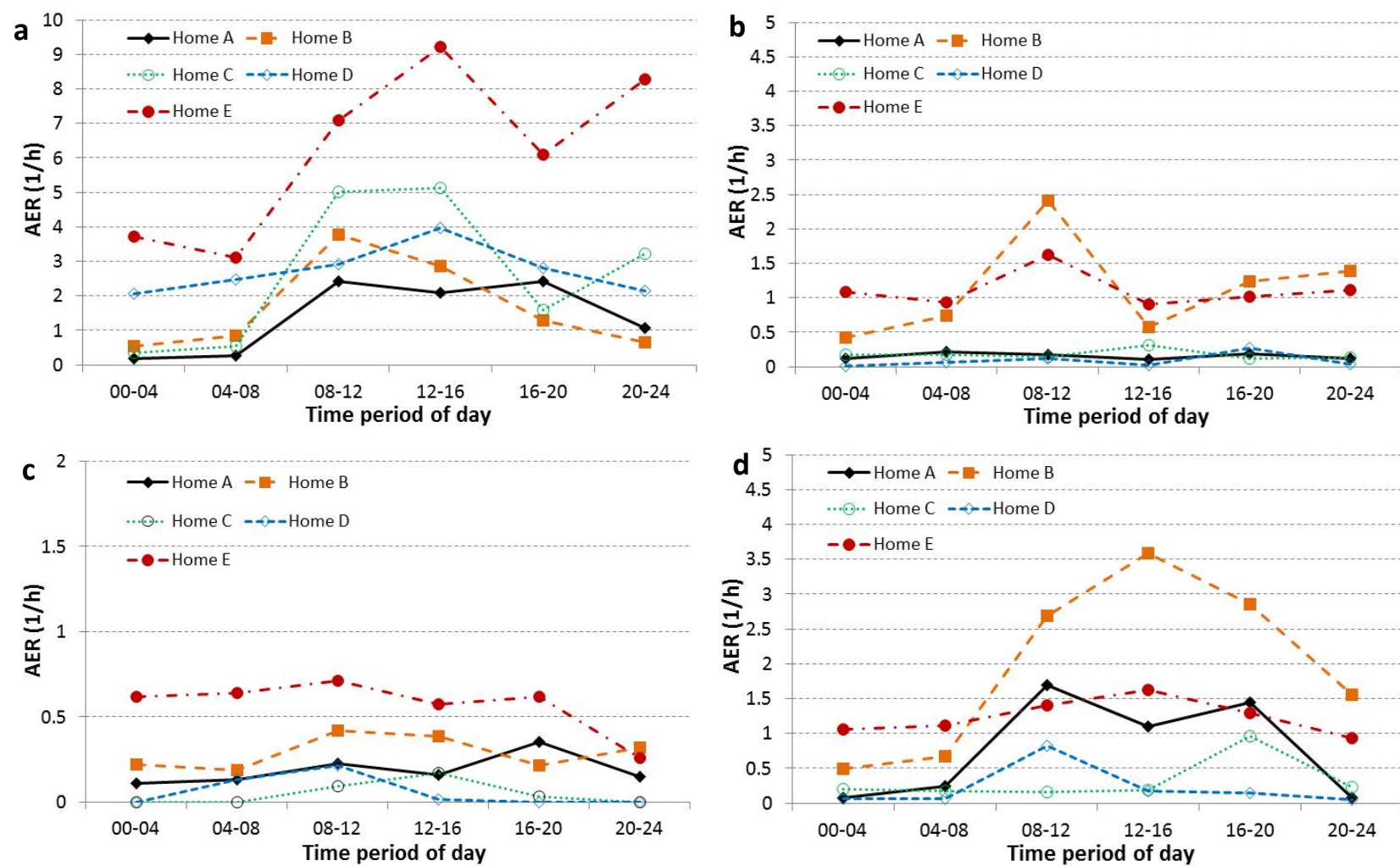

Figure 1

567

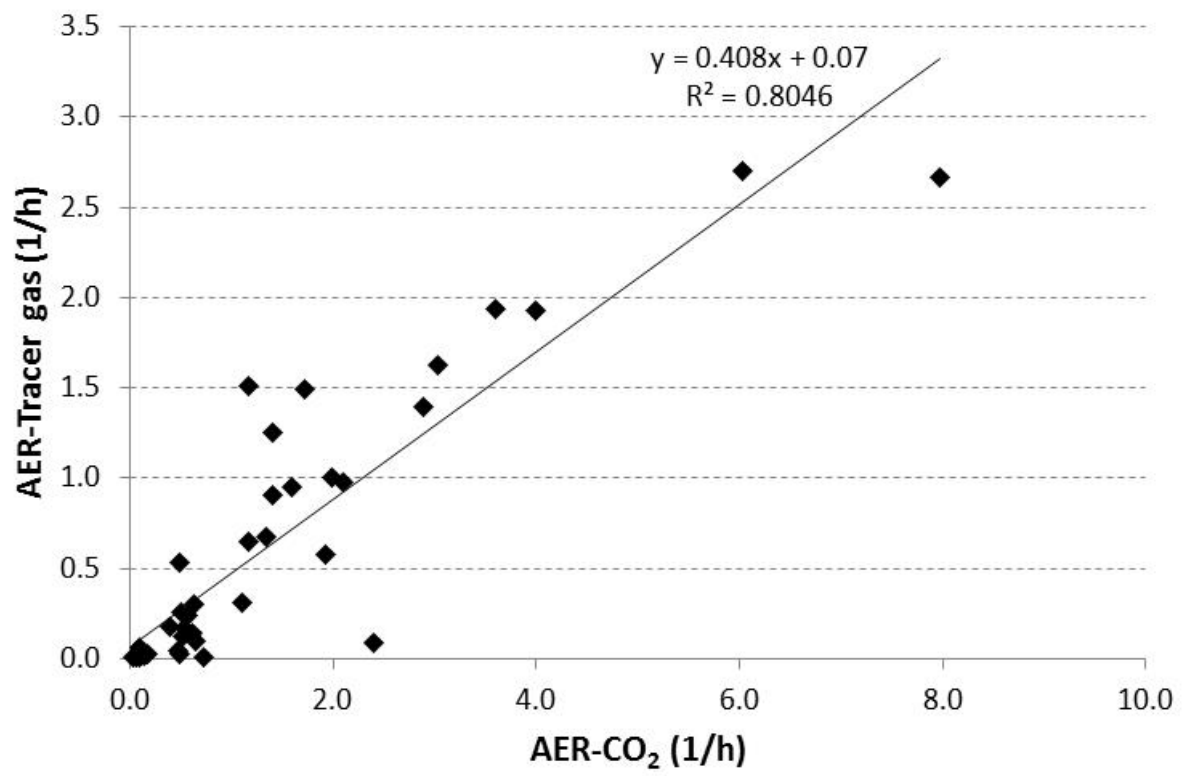

Figure 2 


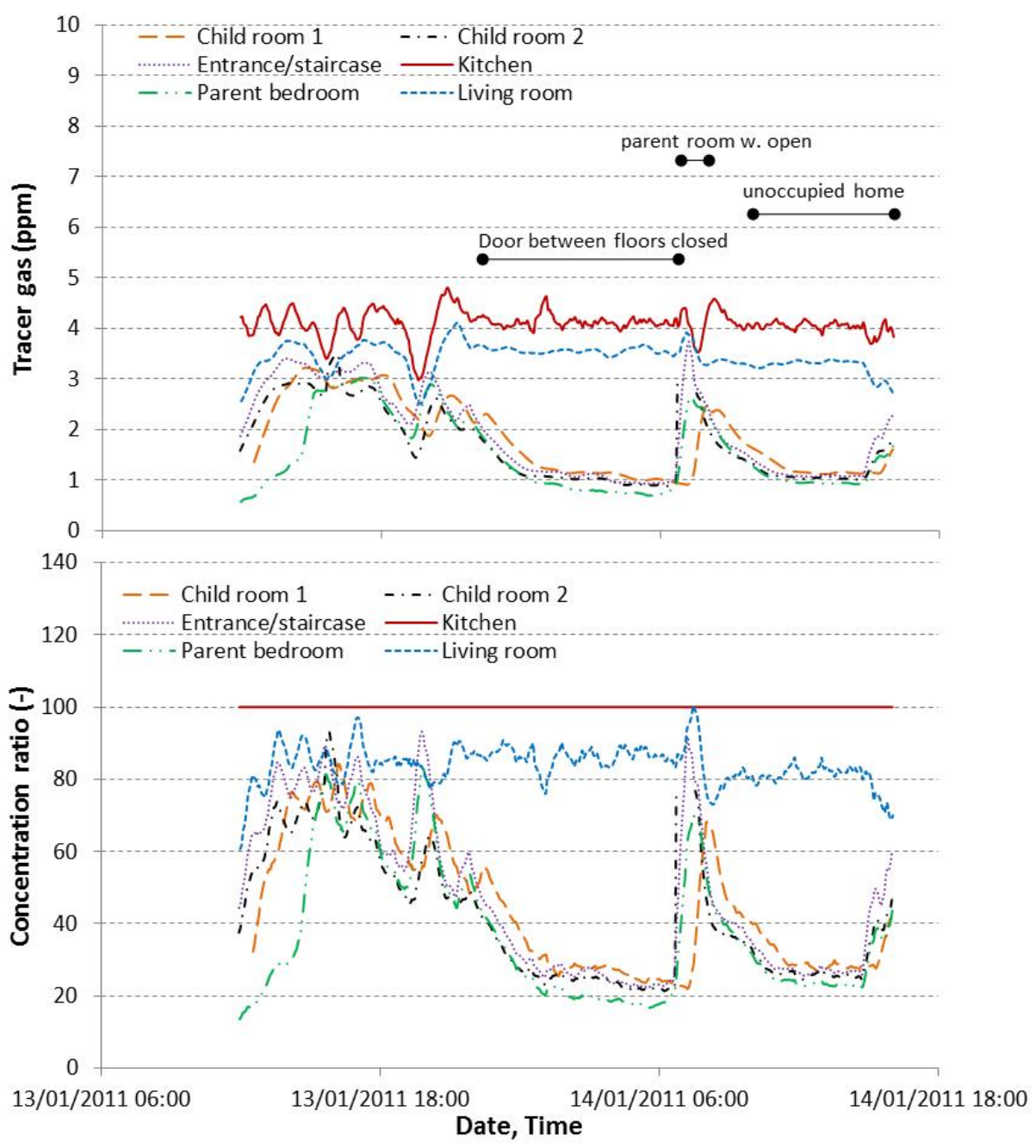

\section{$572 \quad$ Figure 3}




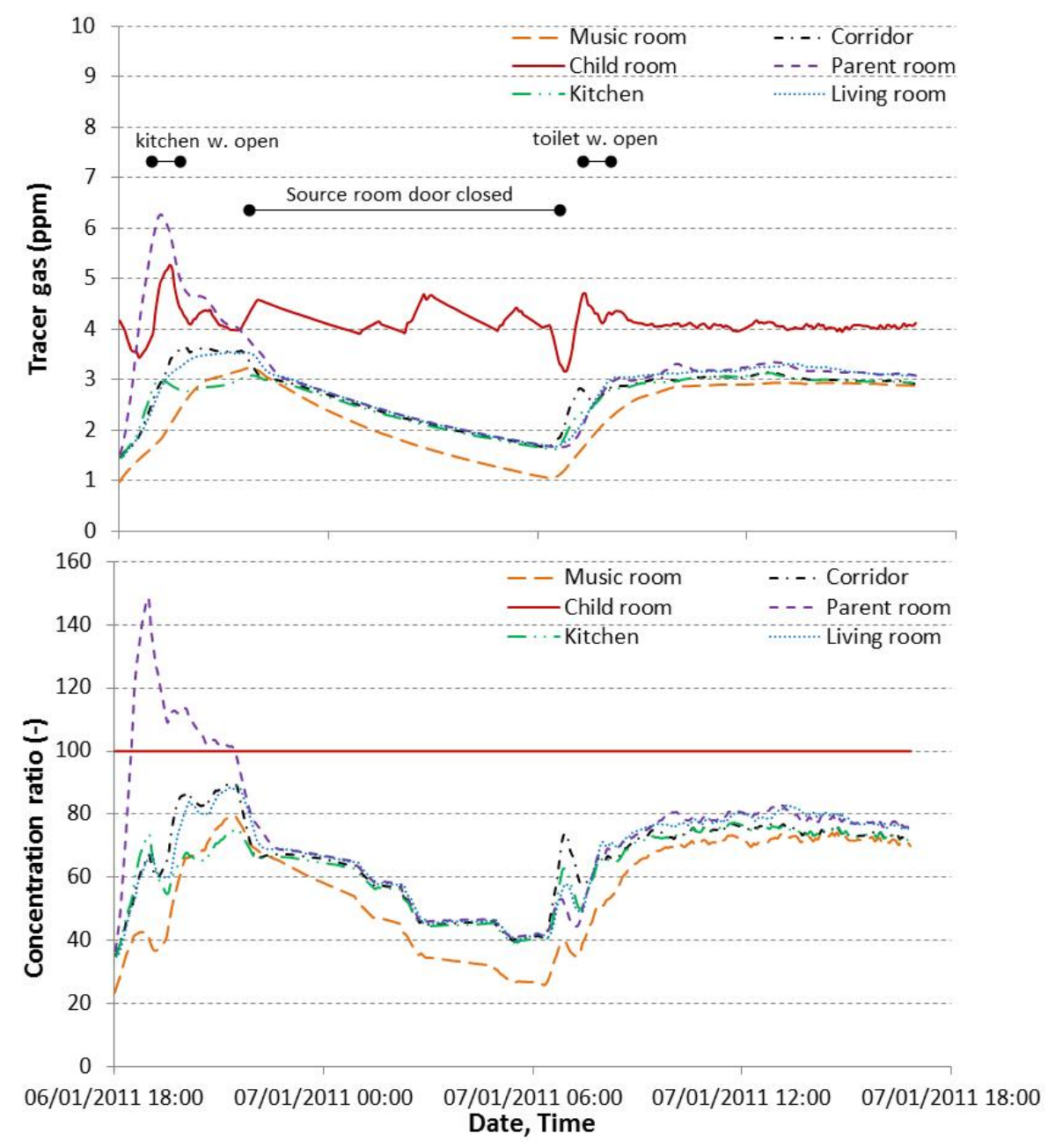

\section{$575 \quad$ Figure 4}


Tables

578 Table 1. Characteristics of the five homes.

\begin{tabular}{|c|c|c|c|c|c|c|c|c|}
\hline Home & $\begin{array}{c}\text { Type / No. of } \\
\text { floors }\end{array}$ & $\begin{array}{c}\text { Construction } \\
\text { year }\end{array}$ & $\begin{array}{c}\text { Occupants } \\
\text { Adults + } \\
\text { children } \\
\end{array}$ & $\begin{array}{c}\text { Floor } \\
\text { area } \\
\left(\mathbf{m}^{2}\right)^{\mathrm{a}}\end{array}$ & $\begin{array}{c}\text { Volume } \\
\left(\mathbf{m}^{3}\right)\end{array}$ & $\begin{array}{c}\begin{array}{c}\% \text { of } \\
\text { volume } \\
\text { measured }\end{array} \\
\end{array}$ & Basement & Ventilation \\
\hline A & Detached / 1 & 1964 & $2+1$ & 117 & 314 & 79.1 & No & Natural ${ }^{\mathrm{c}}$ \\
\hline B & Detached / $2^{\mathrm{b}}$ & 1921 & $2+2$ & $122^{\mathrm{b}}$ & $294^{\mathrm{b}}$ & 96.5 & Yes & Natural ${ }^{c}$ \\
\hline $\mathrm{C}$ & Row house / 1 & 2007 & $2+0$ & 87 & 242 & 87.5 & No & Natural \\
\hline D & Detached / 2 & 1947 & $2+0$ & 170 & 398 & 58.5 & Yes & Natural \\
\hline E & Apartment / 1 & 2004 & $1+0$ & 66 & 172 & 93.0 & No & Bath. exhaust \\
\hline
\end{tabular}

579 a Based on the measured area of each room in the dwelling

$580 \quad{ }^{b}$ Values without basement. With basement $177 \mathrm{~m}^{2}$ and $398 \mathrm{~m}^{3}$. No measurements were made in the basement and the 581 door to the stairs leading to the basement were always closed during the measurements.

${ }^{\mathrm{c}}$ Exhaust fan with manual control present in the bathroom

584

585 Table 2. Air exchange rates in the five homes during four seasons measured by active tracer gas.

586 Each home AER is the volume-weighted average of the AERs of the measured rooms (except last

587 row $^{\text {a). }}$

\begin{tabular}{|c|c|c|c|c|c|c|}
\hline & \multicolumn{5}{|c|}{ Average AER \pm SD $\left(h^{-1}\right)$} & Grand Average $\left(h^{-1}\right)$ \\
\hline Home & $\mathrm{A}$ & B & $\mathrm{C}$ & $\mathrm{D}$ & $\mathrm{E}$ & \\
\hline Summer & $1.38 \pm 0.8$ & $1.60 \pm 0.8$ & $2.36 \pm 0.7$ & $1.91 \pm 1.1$ & $5.40 \pm 1.4$ & 2.53 \\
\hline Autumn & $0.14 \pm 0.5$ & $0.98 \pm 0.9$ & $0.16 \pm 0.2$ & $0.05 \pm 0.04$ & $1.11 \pm 0.4$ & 0.49 \\
\hline Winter & $0.24 \pm 0.4$ & $0.29 \pm 0.2$ & $0.04 \pm 0.01$ & $0.10 \pm 0.2$ & $0.62 \pm 0.7$ & 0.26 \\
\hline Spring & $0.68 \pm 0.3$ & $1.93 \pm 0.8$ & $0.32 \pm 0.2$ & $0.20 \pm 0.1$ & $1.22 \pm 0.6$ & 0.87 \\
\hline All seasons ${ }^{a}$ & 0.52 & 1.17 & 0.63 & 0.36 & 1.97 & - \\
\hline
\end{tabular}

${ }^{a}$ based on overall AERs in each house within each season, calculated from the total airflow into the measured rooms (sum of average flows for each room) and the total volume of these rooms. 
Table 3. Air exchange and ventilation rates in all measured rooms during periods when the homes were actively occupied (excluding nights), during night periods (00:00-06:00) and unoccupied

595 periods.

\begin{tabular}{|c|c|c|c|c|c|}
\hline & $\mathrm{N}$ & $\begin{array}{c}\text { Average } \\
\text { AER } \pm \text { SD } \\
\left(\mathrm{h}^{-1}\right)\end{array}$ & $\begin{array}{c}\text { Median } \\
\text { AER } \\
\left(\mathrm{h}^{-1}\right)\end{array}$ & $\begin{array}{c}\text { Average } \\
\text { vent. rate } \\
\left(\mathrm{L} / \mathrm{s} / \mathrm{m}^{2}\right)\end{array}$ & $\begin{array}{c}\text { Average } \\
\text { window } \\
\text { pos. }^{\text {a }}\end{array}$ \\
\hline \multicolumn{6}{|l|}{ All seasons } \\
\hline Occupied - day & 96 & $1.20 \pm 1.44$ & 0.59 & 0.84 & 0.37 \\
\hline Night & 96 & $0.48 \pm 0.72$ & 0.17 & 0.33 & 0.24 \\
\hline Unoccupied & 66 & $0.93 \pm 2.48$ & 0.27 & 0.66 & 0.07 \\
\hline \multicolumn{6}{|l|}{ Summer } \\
\hline Occupied - day & 24 & $2.82 \pm 1.68$ & 2.70 & 2.01 & 0.91 \\
\hline Night & 24 & $0.93 \pm 1.07$ & 0.47 & 0.65 & 0.67 \\
\hline Unoccupied & 19 & $2.42 \pm 4.31$ & 0.87 & 1.73 & 0.18 \\
\hline \multicolumn{6}{|l|}{ Autumn } \\
\hline Occupied - day & 24 & $0.53 \pm 0.82$ & 0.20 & 0.36 & 0.16 \\
\hline Night & 24 & $0.37 \pm 0.49$ & 0.10 & 0.26 & 0.12 \\
\hline Unoccupied & 9 & $0.48 \pm 0.32$ & 0.36 & 0.33 & 0.00 \\
\hline \multicolumn{6}{|l|}{ Winter } \\
\hline Occupied - day & 24 & $0.39 \pm 0.44$ & 0.24 & 0.26 & 0.10 \\
\hline Night & 24 & $0.24 \pm 0.36$ & 0.13 & 0.16 & 0.02 \\
\hline Unoccupied & 14 & $0.32 \pm 0.42$ & 0.17 & 0.21 & 0.00 \\
\hline \multicolumn{6}{|l|}{ Spring } \\
\hline Occupied - day & 24 & $1.07 \pm 0.98$ & 0.67 & 0.74 & 0.33 \\
\hline Night & 24 & $0.40 \pm 0.56$ & 0.14 & 0.26 & 0.20 \\
\hline Unoccupied & 24 & $0.28 \pm 0.27$ & 0.18 & 0.20 & 0.05 \\
\hline
\end{tabular}

${ }^{\text {a }}$ Values assigned to the position of the windows for each time step of AER measurement: $0=$ closed, $1=$ ajar, $2=$ open. The average window position is a time-weighted continuous variable.

$\mathrm{p}<0.001$ for difference in AER between occupied and night periods ( $\mathrm{n}=96)$ and between occupied and unoccupied periods ( $n=66)$. No significant difference was observed between night and unoccupied periods ( $n=66$ ); Window opening was significantly different between all three periods (Wilcoxon matched-pairs signed-rank test; all seasons combined)

Table 4. Bedroom air exchange rates measured by active tracer gas (constant concentration in the entire home) and by occupant generated $\mathrm{CO}_{2}$ during identical night periods. Whole-house monthly AERs from passive tracer gas during the months corresponding to the other measurements are shown for comparison.

\begin{tabular}{|c|c|c|c|c|c|c|c|c|c|c|}
\hline & \multicolumn{4}{|c|}{$\begin{array}{l}\text { AER-Tracer gas } \\
\qquad\left(\mathrm{h}^{-1}\right)\end{array}$} & \multicolumn{3}{|c|}{$\begin{array}{c}\mathrm{AER}-\mathrm{CO}_{2} \\
\left(\mathrm{~h}^{-1}\right)\end{array}$} & \multicolumn{2}{|c|}{$\begin{array}{l}\mathrm{AER}-\mathrm{CO}_{2} / \mathrm{AER}- \\
\text { Tracer gas ratio }\end{array}$} & \multirow{2}{*}{$\begin{array}{c}\text { PFT }(\mathrm{n}=5 \text { per } \\
\text { season, } 17 \text { for } \\
\text { All s. })^{c} \\
\left(\mathrm{~h}^{-1}\right) \\
\text { Average }\end{array}$} \\
\hline & $\mathrm{N}$ & Average & $\mathrm{SD}$ & Median & Average & SD & Median & Average & Median & \\
\hline Summer $^{\mathrm{a}}$ & 10 & 1.22 & 0.92 & 1.12 & 2.88 & 2.35 & 2.25 & 4.7 & 2.11 & 1.02 \\
\hline Autumn ${ }^{a}$ & 9 & 0.44 & 0.64 & 0.14 & 1.07 & 1.14 & 0.62 & 4.9 & 4.41 & 0.64 \\
\hline Winter $^{\mathrm{a}}$ & 10 & 0.22 & 0.29 & 0.10 & 0.48 & 0.41 & 0.50 & 10.5 & 3.16 & 0.68 \\
\hline Spring a & 10 & 0.65 & 0.75 & 0.24 & 1.12 & 1.22 & 0.80 & 5.26 & 2.14 & 0.36 \\
\hline All seasons ${ }^{\text {a }}$ & 39 & 0.64 & 0.76 & 0.25 & 1.40 & 1.68 & 0.65 & 6.38 & 2.42 & 0.73 \\
\hline All seasons ${ }^{b}$ & 98 & 0.67 & 0.94 & 0.20 & 1.45 & 2.01 & 0.64 & 11.02 & 2.93 & - \\
\hline \multicolumn{11}{|c|}{$\begin{array}{l}\text { a based on average AERs in each bedroom across all measured nights ( } \mathrm{n}=39 \text { bedroom } \mathrm{n} \\
\text { bedrooms over } 4 \text { seasons, one bedroom was excluded in the autumn due to no occupant } \\
\text { b based on raw AERs obtained for each night in each bedroom ( } \mathrm{n}=98 \text { measured nights) } \\
{ }^{\mathrm{c}} \text { Missing } 3 \text { values for spring }\end{array}$} \\
\hline
\end{tabular}


Table 5. Air exchange rates in the five homes during winter measured by active tracer gas and passive tracer gas applied during the same days. Monthly AER from PFT are indicated for comparison.

\begin{tabular}{|c|c|c|c|c|c|c|}
\hline & \multicolumn{5}{|c|}{$\operatorname{AER}\left(h^{-1}\right)$} & \multirow{2}{*}{ Average $\left(\mathrm{h}^{-1}\right)$} \\
\hline Home & A & B & $\mathrm{C}$ & $\mathrm{D}$ & $\mathrm{E}$ & \\
\hline Tracer gas (by rooms) ${ }^{a}$ & 0.24 & 0.29 & 0.04 & 0.10 & 0.62 & 0.26 \\
\hline Tracer gas (by home) $^{\mathrm{b}}$ & 0.19 & 0.28 & 0.03 & 0.13 & 0.62 & 0.25 \\
\hline PFT (5 days) ${ }^{\mathrm{c}}$ & 0.20 & 1.41 & 0.25 & 0.30 & 0.99 & 0.63 \\
\hline PFT (entire month) ${ }^{c}$ & 0.32 & 1.39 & 0.29 & 0.34 & 1.07 & 0.68 \\
\hline
\end{tabular}

a Volume-weighted average AERs from all measured rooms

${ }^{\mathrm{b}}$ Overall AERs in the house, calculated from the total airflow into the measured rooms (sum of average flows for each room) and the total volume of these rooms

c Based on the total volume of the entire dwellings

Table 6. Average tracer gas concentrations and fractions of source room concentrations in all measured non-source rooms in the five homes. Results stratified by house floor, occupancy and distance from source room (single-floor houses only) are also presented.

\begin{tabular}{|c|c|c|c|c|c|c|c|c|}
\hline & \multicolumn{3}{|c|}{$\begin{array}{l}\text { Source room conc. } \\
\text { (ppm) }\end{array}$} & \multicolumn{3}{|c|}{$\begin{array}{l}\text { Non-source room conc. } \\
\text { (ppm) }\end{array}$} & \multicolumn{2}{|c|}{$\begin{array}{c}\% \text { of source room } \\
\text { conc. }\end{array}$} \\
\hline & $\mathrm{N}$ & $\begin{array}{l}\text { Average } \\
\text { (SD) }\end{array}$ & Median & $\mathrm{N}$ & $\begin{array}{l}\text { Average } \\
\text { (SD) }\end{array}$ & Median & $\begin{array}{l}\text { Average } \\
\text { (SD) }\end{array}$ & Median \\
\hline All seasons & 20 & $4.0(0.6)$ & 4.1 & 92 & $2.3(1.1)$ & 2.5 & $58(26)$ & 62 \\
\hline Summer & 5 & $3.5(0.9)$ & 4.0 & 24 & $1.5(0.9)$ & 1.2 & 46 (23) & 48 \\
\hline Autumn & 5 & $4.1(0.1)$ & 4.1 & 23 & $2.6(1.0)$ & 3.1 & $64(25)$ & 78 \\
\hline Winter & 5 & $4.3(0.2)$ & 4.4 & 23 & $2.8(1.0)$ & 2.7 & 65 (22) & 66 \\
\hline Spring & 5 & $4.1(0.1)$ & 4.1 & 22 & $2.4(1.2)$ & 2.8 & $59(29)$ & 68 \\
\hline $\begin{array}{l}\text { Source floors: 1- } \\
\text { floor homes }{ }^{\text {a }}\end{array}$ & - & - & - & 52 & $2.6(1.0)$ & 2.9 & 67 (20) & 68 \\
\hline $\begin{array}{l}\text { Source floors: 2- } \\
\text { floor homes }^{\text {a }}\end{array}$ & - & - & - & 16 & $3.0(0.6)$ & 3.0 & 72 (16) & 74 \\
\hline $\begin{array}{l}\text { Non-source } \\
\text { floors }\end{array}$ & - & - & - & 24 & $1.2(0.8)$ & 1.1 & $31(21)$ & 27 \\
\hline Zone $2^{\mathrm{a}, \mathrm{b}}$ & - & - & - & 15 & $3.1(0.9)$ & 3.3 & 77 (11) & 82 \\
\hline Zone $3^{\mathrm{a}, \mathrm{b}}$ & - & - & - & 24 & $2.9(0.8)$ & 3.2 & $73(14)$ & 77 \\
\hline Occupied & $16^{\mathrm{c}}$ & $4.1(0.3)$ & 4.1 & 72 & $2.5(1.1)$ & 2.7 & $61(24)$ & 65 \\
\hline Unoccupied & $16^{c}$ & $4.2(0.5)$ & 4.2 & 72 & $2.5(1.3)$ & 3.0 & 61 (29) & 69 \\
\hline
\end{tabular}

${ }^{\mathrm{a}}$ Does not include source room (considered as zone 1); ${ }^{\mathrm{b}}$ Data from two single-floor houses; ${ }^{\mathrm{c}}$ During four measurements the occupants didn’t provide occupancy data $\mathrm{p}<0.05$ for differences between fractions by season; Kruskal-Wallis test $\mathrm{p}<0.001$ for differences in both concentrations and fractions between source floor (all homes combined, n=68) and nonsource floor; Two-sample Wilcoxon rank-sum test and two-sample t-test

No significant difference between occupied and unoccupied periods, or between zone 2 and zone 3. 

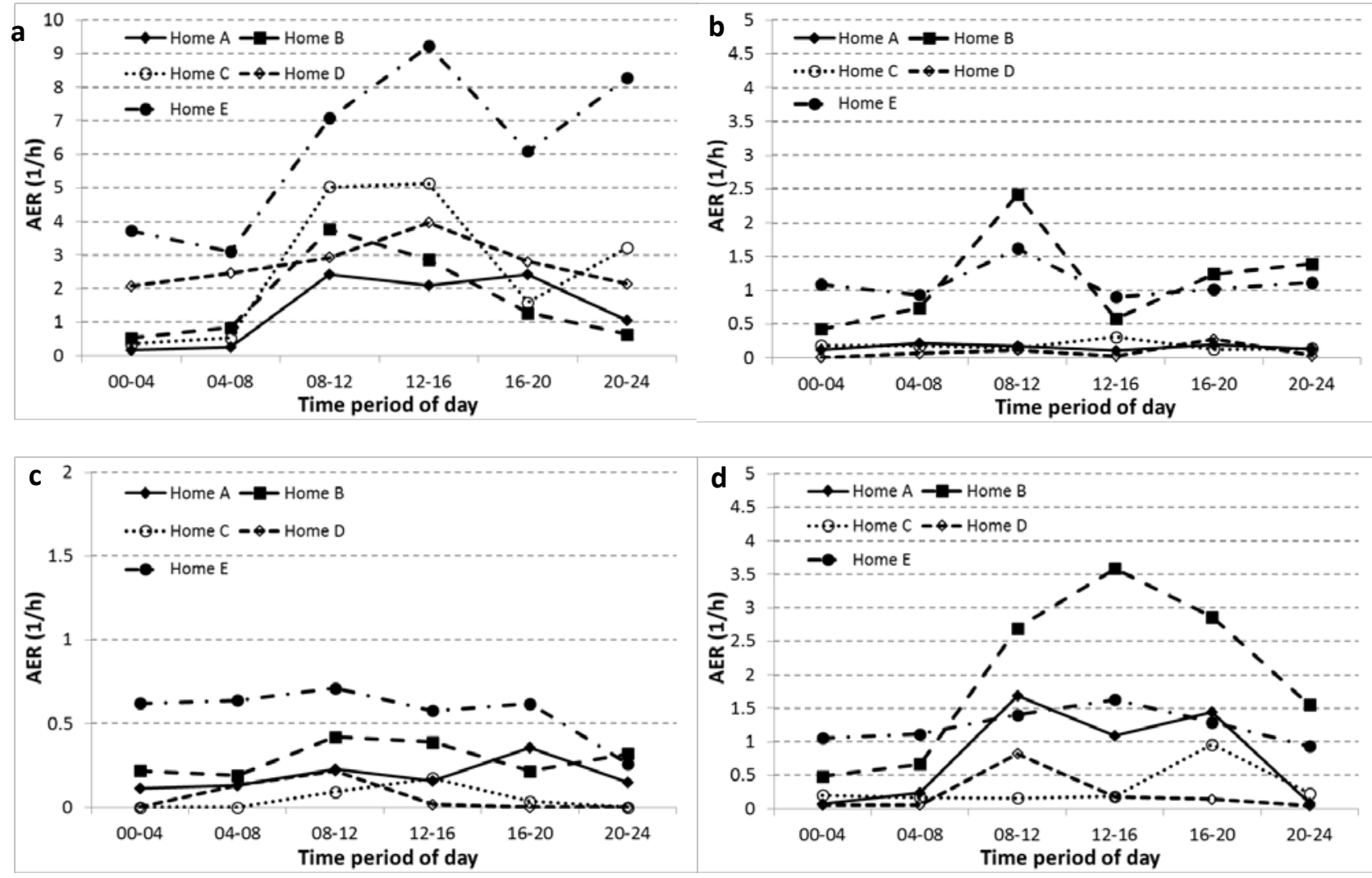

Figure 1 - B\&W for print 


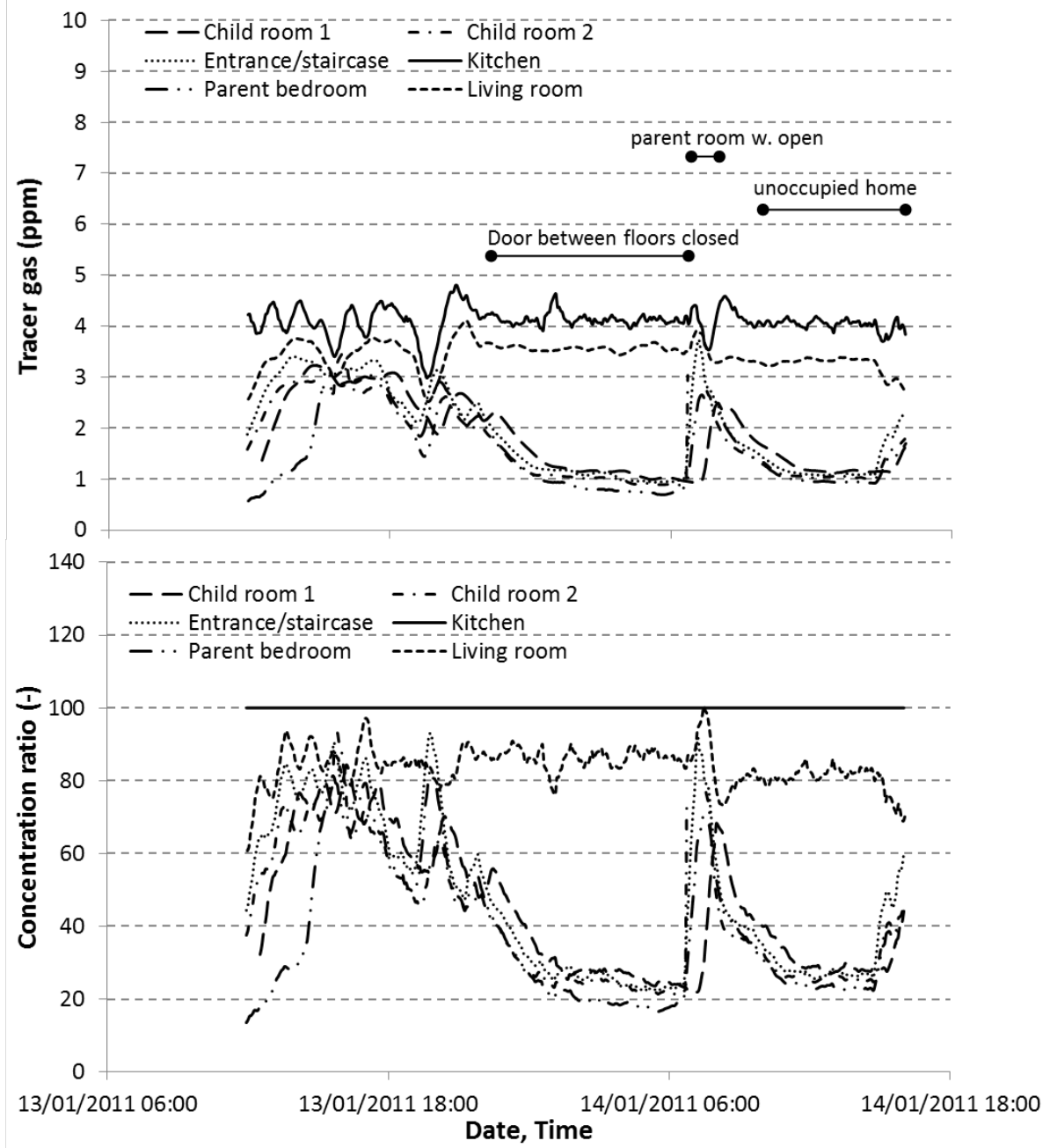

638 Figure $3-\mathrm{B} \& \mathrm{~W}$ for print 


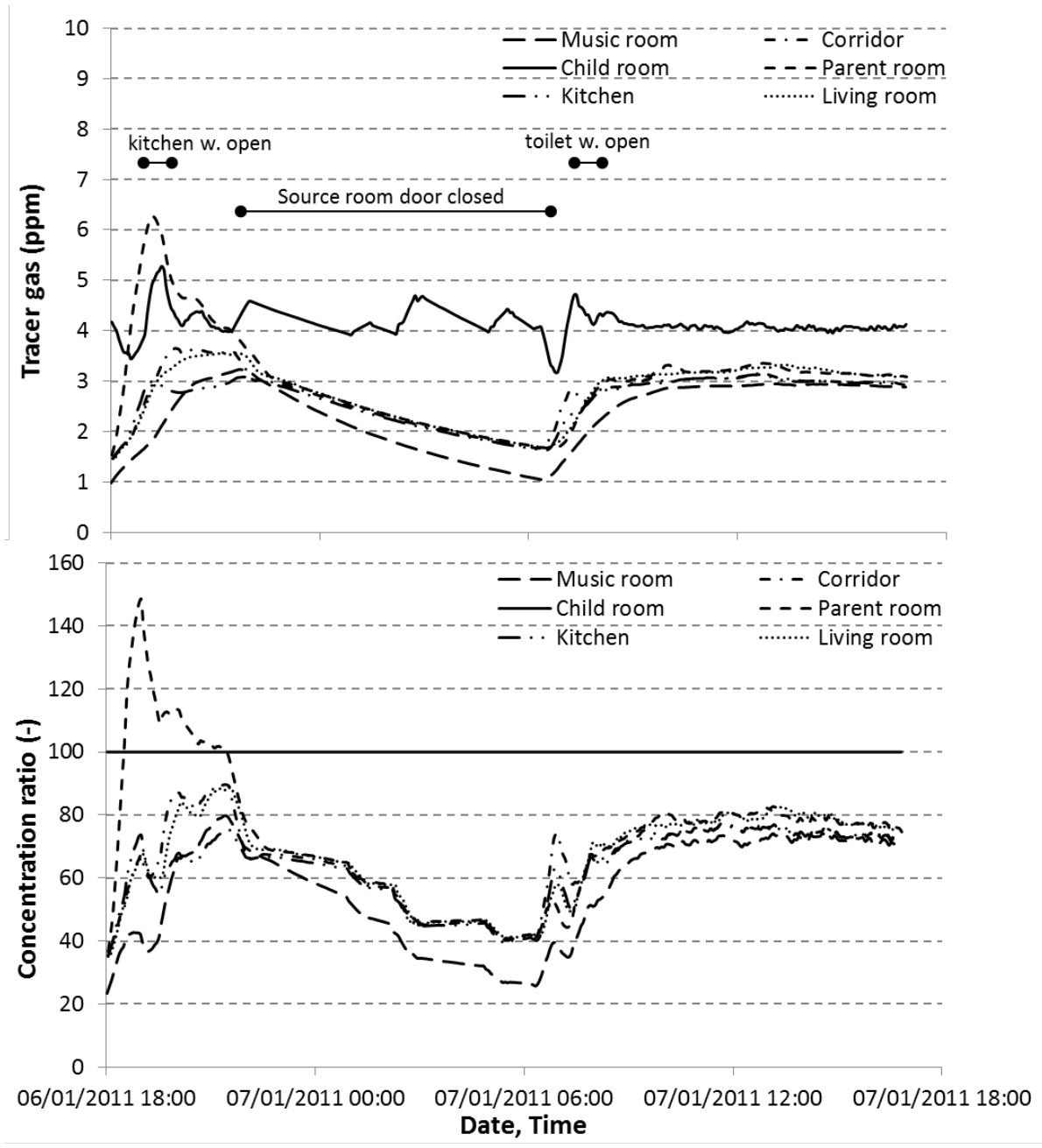

641 Figure $4-B \& W$ for print 